\title{
SELECTING PORTS AND TERMINAL OPERATORS - AN APPLICATION OF PSO
}

Tzay-An Shiau

Department of Harbor and River Engineering, National Taiwan Ocean University, Keelung, Taiwan, R.O.C.

Li-Mei Lin

Department of Harbor and River Engineering, National Taiwan Ocean University, Keelung, Taiwan, R.O.C., dttpdd02@klhb.gov.tw

Ding-Hsun Hsiao

Keelung Harbor Bureau, Keelung, Taiwan, R.O.C.

Follow this and additional works at: https://jmstt.ntou.edu.tw/journal

Part of the Engineering Commons

\section{Recommended Citation}

Shiau, Tzay-An; Lin, Li-Mei; and Hsiao, Ding-Hsun (2011) "SELECTING PORTS AND TERMINAL OPERATORS - AN APPLICATION OF PSO," Journal of Marine Science and Technology. Vol. 19: Iss. 5, Article 5.

DOI: $10.51400 / 2709-6998.2163$

Available at: https://jmstt.ntou.edu.tw/journal/vol19/iss5/5

This Research Article is brought to you for free and open access by Journal of Marine Science and Technology. It has been accepted for inclusion in Journal of Marine Science and Technology by an authorized editor of Journal of Marine Science and Technology. 


\title{
SELECTING PORTS AND TERMINAL OPERATORS - AN APPLICATION OF PSO
}

\author{
Tzay-An Shiau*, Li-Mei Lin*, and Ding-Hsun Hsiao**
}

Key words: port, particle swarm optimization, container terminal.

\begin{abstract}
Past literature has mostly discussed port selection. However, within a given region, any port which meets a carrier's threshold conditions is eligible for consideration, and a terminal operator at any of these ports is a candidate for entering into a contract with the carrier. The choice is not restricted to terminal operators at a single given port. Thus the choice of terminal operator between ports within a given region is an important issue in the decision-making process and has rarely been addressed in the literature. The main purpose of this paper is to examine a situation in which all ports in a country or region meet the minimum criteria set by carriers, and how carriers then select terminal operators.
\end{abstract}

\section{INTRODUCTION}

The selection of ports and the factors involved in making the selection are important to carriers, shippers, cargo owners, third party logistics providers and port (or terminal) managers. The literature on the subject of port selection is always enormous in quantity. Authors $[2,13]$ have argued that the carrier is the key decision maker in the selection of ports. Tongzon [14] finds that in fast-developing supply chains, shippers consider logistics services throughout the entire supply chain. They do not focus exclusively on port selection, which is just one of several important factors within the logistics system. Accordingly, the influence of cargo owners and shippers on port selection is declining. Third party logistics providers, who coordinate delivery from origin to destination via several different shippers, have become the major decision-makers.

Port selection is complicated by several limiting factors. First, most carriers do not use or operate ports in close proximity to each other. When there is a need to load/unload at a different port in the same region, cargo may be sent using an associated carrier [10]. Second, port charges are very difficult

Paper submitted 12/04/09; revised 03/22/10; accepted 05/21/10. Author for correspondence: Li-Mei Lin (e-mail: dttpdd02@klhb.gov.tw).

*Department of Harbor and River Engineering, National Taiwan Ocean University, Keelung, Taiwan, R.O.C.

**Keelung Harbor Bureau, Keelung, Taiwan, R.O.C.

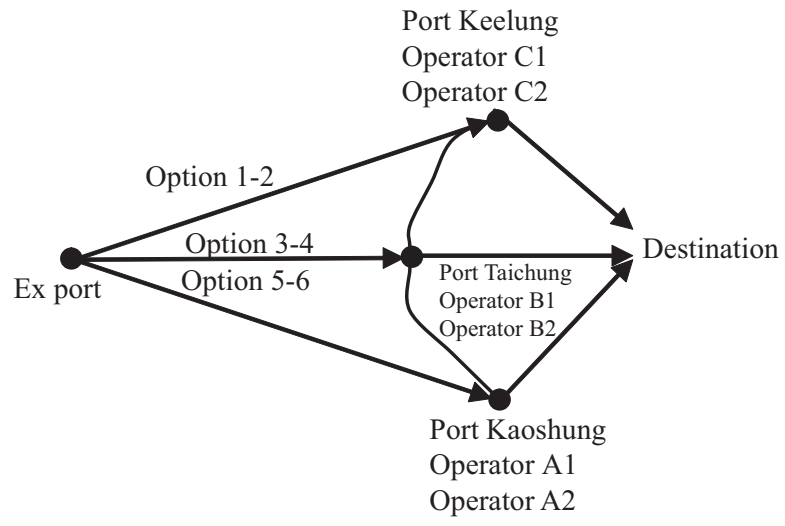

Fig. 1. The frame structure of the transmitted bit stream.

to estimate because of their complexity and because of the form of contracts for certain services. Carriers often sign contracts with ports in which prices are based on guaranteed cargo quantities. Published port tariffs are applicable only to irregular users of port services. In addition, carriers may operate terminals at some ports, and use public terminals at others.

The archetypal model is carriers which do not own or operate terminals. These carriers generally have a two stage decision making process: first they select the port for a given shipment, and then they select a terminal operator at the chosen port. This process involves consideration of a multiplicity of factors, including port performance across a range of indicators. This paper suggests that ports are selected not necessarily on the basis of being the best in any set of indicators; rather they must have acceptable performance level on all indicators. These acceptable limits form a threshold in port selection, not a single decisive criterion. For example, shipping lines may select any port which offers dwelling time within acceptable limits.

Terminal operator selection has rarely been addressed in the literature contrast to port selection. The main contribution of this paper is to examine a situation in which all ports in a country or region meet the minimum criteria set by shipping lines, and how shipping lines then select terminal operators within this country or region. Taking Taiwan as an example, the six terminal operator options available to shipping lines bringing cargo into Taiwan are shown in Fig. 1. Previous literature [1,9, $10,13,14]$ suggests that the criteria for port selection depend 
on both the port user and the type of cargo, therefore this paper focuses its analysis on carriers.

The rest of this paper is organized as follows. Section 2 discusses the research methods and tools employed in this paper. Section 3 develops a mathematical programming model, and using Particle Swarm Optimization (PSO) technique to solve the optimal solution. Section 4 applies the model to the ports of Keelung, Taichung and Kaohsiung in Taiwan. Finally, conclusions and suggestions are summarized in Section 5.

\section{RESEARCH METHODS}

\section{Mathematical Programming Model}

Two main approaches have been used in research on the problem defined in Section 1: statistical (probabilistic) and mathematical programming approaches. Statistical techniques allow the weighting of ports (or terminal operators) using probabilistic scheme or find relevant factors by dividing ports (or terminal operators) into groups. However, these techniques can only derive factors relevant to the suitability of a given port (or terminal operator), which are then used in the next stage of decision making. In order to deal with these problems of indefiniteness and a lack of explicit standards, researchers have used questionnaires to gather data on the decisions of a large number of carriers or other organizations, and to derive effective selection models [9].

The selection of a terminal operator in a given region is an optimization problem. Optimization theory has been applied in many fields: production planning, product design, construction schedules, economic management and control systems, etc. Cost factors have also been included into port selection model in recent researches, and the model is no longer limited to the traditional selection of a single port. Shipping routes are diversifying. The goals of carriers now are not just port selection, but improvement of quality and minimization of costs. These additional factors complicate the issue, so it is necessary to apply mathematical programming [6]. Mathematical programming involves quantitative principles, so effective models of the problem can be generated and used to develop solutions. There have been many studies on port (or supplier) selection taking total costs into consideration.

Benton [1] notes that when discounts are applied in the mathematical programming, the model becomes complex and too difficult to solve for commercial software. The models must therefore be redeveloped or heuristic techniques used. The aim of heuristic techniques is to reduce the program. Even when the optimal solution cannot be found within the time available, a good solution can be obtained for reference during decision-making. Early heuristic methods focused on simulating biological functions or evolutionary phenomena. Genetic Algorithm (GA), Simulated Annealing (SA) and PSO are the methods most often applied to structure optimization.

In recent years, heuristic search methods have focused on simulating behavior in social systems: "swarm intelligence", intelligent behavior which emerges from systems of large

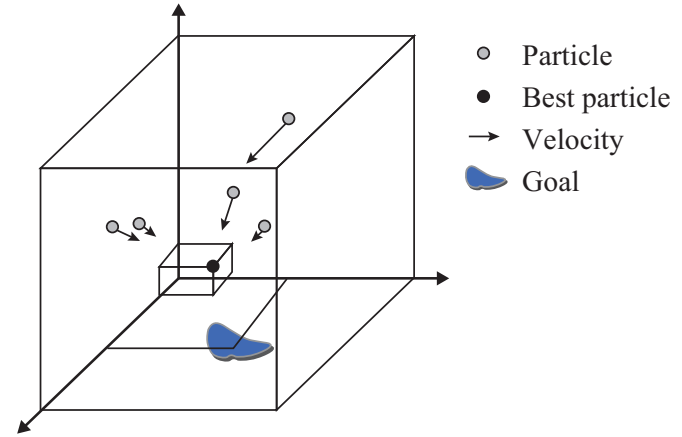

Fig. 2. Movement of particles in a PSO model [12].

numbers of simple individual, such as fish shoals or flocks of birds. These collectives are simulated in order to find optimal behavior patterns. PSO is one such model, using population dynamics to optimize nonlinear functions. Within a socialized group, the behavior of each individual is affected not only by its perceptions and past experiences, but also by the group behavior of the society [5].

The main advantage of PSO is that only the particles with the best level of fitness need be tracked for speed and direction This makes the technique fairly simple, and it is not necessary to adjust the parameters very often [5]. In this paper, PSO, proposed by Eberhart and Kennedy [4], is applied to solve the Mixed Integer Programming (MIP) model derived from the terminal operator choice problem.

\section{PSO}

Eberhart and Kennedy [4] discuss a PSO model of foodseeking behavior in flocking birds. PSO assumes that there is only a single food source in a given region, and individuals do not know how far they are from the food source. Each bird is modeled as a particle. For each particle, the best strategy for finding the food source is searching around the position of the individual nearest to the food source. The most important feature of the model is that particles can exchange information about their past experiences. This feature allows the flock (of birds, or swarm of particles) to progress towards the food source, as in Fig. 2.

In PSO, each solution is conceived of as a bird, and is called a "particle". A fitness function is calculated for each particle to determine the fitness of its current position, and each particle must have memory so that it can remember the position in which it experienced its highest level of fitness. Each particle also has a speed, which determines its direction of flight and how far it goes each iteration. The calculations for PSO are as follows [11].

(1) Initial: the particles are generated in a k-dimensional space with random positions and speeds.

(2) Evaluation: the value of the fitness function must be assessed for each particle to determine its fitness for the objective function. The fitness function is the mathematical 
programming model above.

(3) Fine the $P_{\text {best }}$ : each particle's current fitness is constantly compared to its previous fittest solution, and in the next iteration it moves to improve its fitness.

(4) Fine the $G_{\text {best }}$ : individual bests and global bests are compared, and if the individual best is more fit than the global best, then the global best is updated.

(5) Update the Velocity: this paper applies the concept of inertia weight, introduced by Shi and Eberhart [11]. The particle velocity and position functions are:

$$
\begin{gathered}
V_{i d}=W \times V_{i d}+C_{1} \times \operatorname{Rand}() \times\left(P_{i d}-X_{i d}\right)+C_{2} \times \operatorname{Rand}() \\
\times\left(P_{g d}-X_{i d}\right) \\
X_{i d}=X_{i d}+V_{i d}
\end{gathered}
$$

where $V_{i d}$ calls the velocity for particle $i$, represents the distance to be traveled by this particle from its current position, $X_{i d}$ represents the particle position, $P_{i d}$ represents its best previous position (i.e. its experience), and $P_{g d}$ represents the best position among all particles in the population. Rand and rand are two random functions with a range $[0,1] . C_{1}$ and $C_{2}$ are positive constant parameters [4].

$$
\begin{gathered}
V_{i d}^{\text {new }}=W \times V_{i d}^{\text {old }}+c_{1} \times r n d_{1} \times\left(P_{i d}-X_{i d}^{\text {old }}\right)+c_{2} \times r n d_{2} \\
\times\left(P_{g d}-X_{i d}^{\text {old }}\right) \\
X_{i d}^{\text {new }}=X_{i d}^{\text {old }}+V_{i d}^{\text {new }}
\end{gathered}
$$

where $V_{i d}^{\text {new }}$ calls the new velocity of particle $i ; V_{i d}^{\text {old }}$ represents the previous velocity of particle $i ; W$ represents the inertia weight; $P_{i d}$ is $P_{b e s t} ; P_{g d}$ is $G_{b e s t} ; X_{i d}{ }^{\text {new }}$ represents the new position of particle $i ; X_{i d}^{\text {old }}$ represents the previous position of particle $i ; c_{1}$ and $c_{2}$ are acceleration coefficients; $r n d_{1}$ and $r n d_{2}$ are random numbers and uniform distribution between 0 and 1 .

(6) If a stop criterion is met, then stop; otherwise, loop to step 2 and continue. Stop criteria is generally a predetermined number of iterations.

\section{MODEL FOR SELECTING TERMINAL OPERATOR}

\section{Carriers}

Maritime cargo carriers have the following characteristics:

(1) A shipping route will pass through several regions, and each region will offer several port options (in Taiwan, Keelung, Taichung and Kaohsiung). Once a port is selected, a carrier then has a choice of terminal operators.

(2) The loading rate of a terminal operator is limited by the number of terminals it operates. The type of vessel it receives also affects the length of the berth windows it can offer.

(3) Some carriers, operating multiple routes, may bring to a single port a greater cargo throughput than one terminal operator can handle. When several vessels arrive at a single port at the same time, it may be necessary to use a second terminal operator. Because each operator has different tariffs, the allocation of vessels and cargos to different operators becomes an important operational issue.

(4) There is a variation in the requirements at port and the costs associated with different types of cargo. Cargo types requiring different services include: import \& export cargo, transshipped and transferred cargo, special cargo, and cargo in import and export container yards and inland distribution centers. A carrier may therefore choose to use more than one operator to deal with different cargo types (e.g., for shipside loading it is necessary to arrange and pay for haulage, an inland distribution point, etc.).

The two key factors affecting carrier selection of port or terminal operator are cost and speed of (un)loading. Loading speed affects port costs, but it can also affect a ship's berth windows at other ports along its route, and thus the costs of the entire shipping route. In this study, minimizing berthing costs is taken as a target, while constraints include the capacity, speed and berthing time provided by terminal operators. Cargo losses in ports also affect the business and costs of carriers, so the damage rate is also an important factor.

\section{Assumptions and Limitations}

The model is bound by the following assumptions and limitations.

(1) Carriers operate multiple lines with multiple types of cargo within the given region.

(2) Ports and terminal operators differ only in the following factors: (un)loading speed, damage rate, capacity, berthing window, berthing rates. Otherwise, all ports and terminal operators are assumed to be equal, or not significantly different.

(3) Carriers cannot select a terminal operator which does not provide the services the carrier requires.

(4) The harbor costs of terminal operators within one port are assumed to be equal. Harbor services such as tugs, pilotage, refueling and provision of water are assumed to cost the same for each operator.

(5) In order to simplify the model, all kinds of services (storage for any number of days, equipment use, securing and management of cargo) for all kinds of cargo (Container Yard (CY), Container Freight Station (CFS), transshipments, air freight, refrigerated containers) are paid for at a packaged rate. Terminal operators differ only in the rates they charge.

(6) In order to simplify the model, all services by external 
freight haulers (irrespective of distance, handling etc.) for all kinds of cargo (CY, CFS, transshipments, air freight, and refrigerated containers) are paid for at a fixed rate. Haulers differ only in the rates they charge.

(7) There are no discounts for volume on costs incurred outside the port.

(8) There is an upper limit on the capacity of any terminal operator (no. of terminals/gantries, optimum (un)loading rates and times). In any given unit of dwelling time, the work completed by the terminal operator cannot exceed this maximum capacity.

(9) The damage rate for a selected terminal operator may not be higher than the minimum requirement of the carrier.

(10) Time spent at each port and loading rates may not be lower than the minimum requirements of the carrier.

(11) Terminal operators have costs in addition to their costs for port services. The other charges they impose on carriers (for administration, legal consultancy, forms, interest on payments, visits, transport, document fees, etc.) are grouped together as transaction costs.

(12) Terminal operators are assumed to have the capacity to provide all of the storage demanded by carriers.

(13) Tariffs are assumed to be constant over the period of the study, unaffected by inflation or other factors.

(14) A carrier operating more than route through a port can select to give all of its business to a single terminal operator, if the total cargo does not exceed the operator's capacity. Conversely, where more than one carriers operate on a single route, they may select to give their business to different terminal operators.

(15) Vessels can leave once cargo operations are complete, so dwelling time is assumed to be equal to the time required for (un)loading.

\section{Mathematical Model}

The costs of using a port are modeled as: fixed costs associated with using the terminal operator (including the costs of travel from the previous port to the current port, as well as port costs); transaction costs; fixed costs from loading damages; costs associated with different types and quantities of cargo; variable costs that are incurred outside the port (freight haulage and distribution center costs); variable costs associated with damage to cargo from loading damages. Based on these factors and Kasilingam and Lee [7], the MIP model is demonstrated as below:

$$
\begin{array}{ll}
\text { Min } & \text { total system costs } \\
\text { s.t. } & \text { (1) loading capacity limits } \\
& \text { (2) dwelling time limits } \\
& \text { (3) damage rate limits }
\end{array}
$$

where, decision variables are:

$x_{i j}$ : throughput of terminal operator $j$ to handle cargo type $i$

$y_{j}=\left\{\begin{array}{l}1, \text { if terminal operator } j \text { is selected } \\ 0, \text { otherwise }\end{array}\right.$ and, parameters are:

$a_{i j}$ : cost of a damage unit when terminal operator $j$ handling cargo type $i$

$c_{i j}{ }^{k}$ : tariff offered by terminal operator $j$ for handling cargo type $i$ at discount level $k . \quad c_{i j}{ }^{0}$ represents the basic, undiscounted price;

$D_{i}$ : the demand for handling cargo type $i$;

$d_{i j}$ : costs incurred outside the port during the handling of cargo type $i$ by terminal operator $j$;

$e_{i j}$ : transaction costs other than port costs;

$f_{j}$ : $\quad$ fixed costs associated with selecting terminal operator $j$;

$H_{i j}{ }^{k}$ : the volume of cargo type $i$ which terminal operator $j$ handles at discount level $k . H_{i j}{ }^{0}=0$;

$i$ : $\quad$ cargo type, $i=1,2, \ldots, n$;

$j: \quad$ terminal operator, $j=1,2, \ldots, m$;

$K_{i j}$ : discount level offered by terminal operator $j$ when handling cargo type $i, k=0,1,2, \ldots, K_{i j}$;

$L: \quad$ longest permitted dwelling time;

$l_{j}$ : dwelling time associated with terminal operator $j$;

$m$ : number of terminal operators;

$n$ : number of cargo types;

$Q_{i}$ : highest permitted damage rate for cargo type $i$;

$q_{i j}$ : damage rate for cargo type $i$ recorded by terminal operator $j$;

$V_{i j}$ : capacity of terminal operator $j$ to handle cargo type $i$;

A step model of discounts developed by Yeh [15] is used. Yeh's model optimal procurement policies for multi-product multi-supplier with capacity constraint and price discount (5):

$$
\begin{gathered}
F\left(x_{i j}\right)=C_{i j}^{0} x_{i j}, H_{i j}^{0}=x_{i j}<H_{i j}^{1} \\
F\left(x_{i j}\right)=C_{i j}^{1} x_{i j}, H_{i j}^{1}=x_{i j}<H_{i j}^{2} \\
\cdots \\
F\left(x_{i j}\right)=C_{i j}^{k} x_{i j}, H_{i j}^{k}=x_{i j}
\end{gathered}
$$

The objective function for minimizing total cost incorporating discount can be expressed as formula (6); the constraints are listed from formula (7) to (12):

$$
\begin{aligned}
\underset{\left\{x_{i j}, \mathrm{y}_{j}\right\}}{\operatorname{Min} T C}= & \sum_{j=1}^{m} f_{j} y_{j}+\sum_{i=1}^{n} \sum_{j=1}^{m} e_{i j} y_{j} \\
& +\sum_{i=1}^{n} \sum_{j=1}^{m}\left[F\left(x_{i j}\right)+x_{i j} d_{i j}+x_{i j} a_{i j} q_{i j}\right] \\
\text { S.t. } \quad x_{i j} \leq V_{i j} y_{j}, \forall i, \forall j & \sum_{j=1}^{m} l_{j} y_{j} \leq L \sum_{j=1}^{m} y_{j} \\
& \sum_{j=1}^{m} q_{i j} y_{j} \leq Q_{i}, \forall i
\end{aligned}
$$




$$
\begin{aligned}
& x_{i j} \geq 0, \forall i, \forall j \\
& \sum_{j=1}^{m} x_{i j}=D_{i}, \forall i \\
& y_{j} \in\{0,1\}, \forall j
\end{aligned}
$$

\section{Model Notes}

This is a two-stage model. The first stage is the decision on allocation of cargo to terminal operators; the second stage incorporates discounts. Fixed costs are assumed to be calculated as a single payment, while other variable costs are added separately; the costs associated with damages during the handling of various cargo types also vary from operator to operator, so these are separately calculated. Formula (5) expresses discounts for volume as $F\left(x_{i j}\right)$, where discounts are applied in progressive steps based on the volume of business. Formula (6) is the objective function for minimizing costs, including port costs, transaction costs associated with cargo types, discounts, services inside and outside the port, and damage costs. Formula (11) represents the necessity to meet the demand for handling of all cargo types. Formula (7) limits the throughput not exceeds the capacity of the terminal operators. Formulas (8) and (9) represent the longest permissible dwelling times and damage rates for each cargo type. Formula (10) Limits cargo volumes to nonnegative values; formula (12) is a binary integer variable representing the choice of terminal operator.

\section{Algorithm Design}

The PSO algorithm is applied to solve the problems of selecting terminal operators. For MIP model, the PSO solution should be decoded from continuous decision space to discrete decision space. Furthermore, the PSO algorithm may search infeasible solution in the optimization process. Thus, this paper incorporates the penalty function into the objective function and the particle swarm would move towards the feasible direction through the penalty to feasible solution. The revised PSO algorithm is designed as follows:

\section{1) Coding and Decoding Design of Particle}

In the algorithm, $z_{i j}^{d}$ means the position of particle $d$, where subscripts $i$ and $j$ are referred to variable $x_{i j}$ in the mathematical model and the dimension of particle is the multiple of container categories and terminal operators $(n \times m)$. From the formula (7) of the mathematical programming, it is required that each category of container demand volume should be satisfied, that is, the sum of each category of container volume allocated to the terminal operator has to be equal to the container demand volume $\left(\sum_{j=1}^{m} x_{i j}=D_{i}, \forall i\right)$. To satisfy this constraint, its ratio will be referred to decide the allocation volume of variable $x_{i j}$ in decoding process.

Besides, the value of $z_{i j}^{d}$ could be negative, so the ratio of $z_{i j}^{d}$ would be set to be zero while it is below zero in transforming. Thus, only non-negative $z_{i j}^{d}$ should be considered in decoding. In this paper, for each $i$ the set of subscript $j$ of non-negative $z_{i j}^{d}$ is as follows.

$$
\boldsymbol{J}_{i}=\left\{j \mid z_{i j}^{d}>0, \forall j\right\}, \quad \forall i
$$

And it could be decoded via formula (14) while transforming $z_{i j}^{d}$ into $x_{i j}$, where,

$$
x_{i j}=\left\{\begin{array}{cl}
D_{i}\left(z_{i j}^{d} / \sum_{j \in J_{i}} z_{i j}^{d}\right) & \text { if } z_{i j}^{d}>0 \\
0 & \text { if } z_{i j}^{d} \leq 0
\end{array}, \forall i, \forall j\right.
$$

On the other hand, the mathematical programming model of Section 3.3 has two kinds of decision variables $x_{i j}$ and $y_{j}$. If the container volume allocated to terminal operator $j$ is zero then $y_{j}=0$, meaning terminal operator $j$ not employed. On the opposite, it means that terminal operator $j$ is employed and variable $y_{j}$ is decoded via formula (15).

$$
y_{j}=\left\{\begin{array}{ll}
1 & \text { if } \sum_{i=1}^{n} x_{i j}=0 \\
0 & \text { otherwise }
\end{array}, \quad \forall j\right.
$$

\section{2) Design of Penalty Function}

In this paper the mathematical programming model consists of four kinds of constraints, from formulas (7) to (9) and (11). Formula (7) could be processed through decoding and the rest of constraints would be processed through penalty function. The penalty function consists of three parts as below.

a) When the allocation volume violates the ceiling limit of production of terminal operator in formula (8), the function of violation volume is:

$$
u_{1}\left(x_{i j}\right)=\left\{\begin{array}{cl}
x_{i j}-V_{i j} & \text { if } x_{i j}>V_{i j} \\
0 & \text { if } x_{i j} \leq V_{i j}
\end{array}, \quad \forall i, \forall j\right.
$$

b) When the sum of turnaround time violates the maximum turnaround time (L) of each container categories in formula (9), the function of violation volume is:

$$
u_{2}(\mathbf{y})=\left\{\begin{array}{ccc}
\sum_{j=1}^{m} l_{j} y_{j}-L & \text { if } & \sum_{j=1}^{m} l_{j} y_{j}>L \\
0 & \text { if } & \sum_{j=1}^{m} l_{j} y_{j} \leq L
\end{array}\right.
$$


where, $\mathbf{y}$ is the set of variable $y_{j}$, expressed by $y=\left\{y_{j}, j=\right.$ $1, \ldots, m\}$.

c) When the sum of minimum accident rate of employed terminal operator violates the minimum accident rate $\left(Q_{i}\right)$ of each container categories in formula (11), the function of violation volume is,

$$
u_{3}^{i}(\mathbf{y})=\left\{\begin{array}{ccc}
\sum_{j=1}^{m} q_{i j} y_{j}-Q_{i} & \text { if } & \sum_{j=1}^{m} q_{i j} y_{j}>Q_{i} \\
0 & \text { if } & \sum_{j=1}^{m} q_{i j} y_{j} \leq Q_{i}
\end{array}, \quad \forall i\right.
$$

where $\mathbf{y}$ is the set of variable $y_{j}$, expressed by $y=\left\{y_{j}, j=\right.$ $1, \ldots, m\}$.

In accordance with the functions of violation volume in a), b) and c), assuming the penalty value $p_{1}$ given per each unit of allocation volume in formula (8); the penalty value $p_{2}$ given per each unit of allocation volume in formula (9); the penalty value $p_{3}$ given by each unit of allocation volume in formula (11), the penalty function is defined as:

$$
g(\mathbf{x}, \mathbf{y})=p_{1}\left(\sum_{i=1}^{n} \sum_{j=1}^{m} u_{1}\left(x_{i j}\right)\right)+p_{2} u_{2}(\mathbf{y})+p_{3}\left(\sum_{i=1}^{n} u_{3}^{i}(\mathbf{y})\right)
$$

In this paper, we set penalty value $p_{1}=10^{8}, p_{2}=10^{9}$ and $p_{3}=$ $10^{12}$. The fitness will be re-evaluated as follows:

Fitness $=f(x)+$ Penalty

$$
f(x)=\sum_{j=1}^{m} f_{j} y_{j}+\sum_{i=1}^{n} \sum_{j=1}^{m} e_{i j} y_{j}+\sum_{i=1}^{n} \sum_{j=1}^{m}\left[F\left(x_{i j}\right)+x_{i j} d_{i j}+x_{i j} a_{i j} q_{i j}\right]
$$

Penalty $=g(\mathrm{x}, \mathrm{y})$

$$
=p_{1}\left(\sum_{i=1}^{n} \sum_{j=1}^{m} u_{1}\left(x_{i j}\right)\right)+p_{2} u_{2}(\mathrm{y})+p_{3}\left(\sum_{i=1}^{n} u_{3}^{i}(\mathrm{y})\right)
$$

\section{3) Method to Generate Initial Solution}

PSO algorithm is employed to search the optimal solution through the movement process of particle swarm. If the particle swarm of initial solution is scattered unequally or homogeneously, it may reduce the possibility searching the optimal solution via PSO algorithm. Therefore, in this paper the initial solution is generated randomly in order to scatter particle swarm equally. On the other way, to avoid the homogeneity of initial solution, two methods to generate the initial solution are designed and they are employed in the mixed way, described as follows.

a) First it is randomly decided whether to employ the terminal operator or not (the probability of employment is 0.5 ). And then it will be randomly decided each category of solution.
Table 1. Shipping volumes for company A.

\begin{tabular}{|c|c|c|c|c|}
\hline Route & $\begin{array}{c}\text { Full } \\
\text { TEUs }\end{array}$ & $\begin{array}{c}\text { Empty } \\
\text { TEUs }\end{array}$ & $\begin{array}{c}\text { Transshipment } \\
\text { TEUs }\end{array}$ & Total \\
\hline $\mathrm{X}$ & 50,000 & 15,000 & 15,000 & 80,000 \\
\hline $\mathrm{Y}$ & 40,000 & 15,000 & 15,000 & 70,000 \\
\hline $\mathrm{Z}$ & 30,000 & 20,000 & 30,000 & 80,000 \\
\hline Total & 120,000 & 50,000 & 60,000 & 230,000 \\
\hline
\end{tabular}

Table 2. Fixed costs.

\begin{tabular}{|c|c|c|}
\hline $\begin{array}{c}\text { Terminal } \\
\text { operator }\left(y_{j}\right)\end{array}$ & $\begin{array}{c}\text { Fixed handling costs } \\
\left(f_{j}\right)(\text { NTD/20'laden })\end{array}$ & $\begin{array}{c}\text { Other transaction } \\
\text { costs }\left(e_{i j}\right)\end{array}$ \\
\hline$y_{1}$ & 1,200 & 2,000 \\
\hline$y_{2}$ & 1,000 & 1,400 \\
\hline$y_{3}$ & 600 & 1,000 \\
\hline$y_{4}$ & 1,200 & 2,000 \\
\hline$y_{5}$ & 1,000 & 1,400 \\
\hline$y_{6}$ & 600 & 1,000 \\
\hline
\end{tabular}

b) To generate the solution which only one terminal operator is employed, the terminal operator will handle all categories of container demand volume. Suppose $m$ groups of terminal operators divided, and group $j$ means the $j$ terminal operator is employed. This kind of initial solution is extreme solution. It could increase the dispersibility and diverseness of initial solution.

\section{WORKED EXAMPLE}

The data for this example comes from company A. Three of company A's shipping routes and cargo types are selected, but will not be revealed here in order to protect the company's information. Two terminal operators are selected from Keelung, Taichung and Kaohsiung ports, giving a total of six options.

\section{Collect Simulate Data}

(1) $\mathrm{D}_{i}$ : a total demand of 120,000 TEUs per year is necessary for the three lines, plus 50,000 empty TEUs, plus 60,000 transshipment TEUs. See Table 1.

(2) $\mathrm{L}_{i}$ : customers (cargo owners) are particularly concerned about delays in the shipping process. In this paper, the time a cargo spends at port is taken to be identical to the dwelling time. This is true for all cargo types. In this paper, the longest dwelling time permitted by company A is 13 hours.

(3) $\mathrm{Q}_{i}$ : the maximum permitted damage rate for all cargo types is $0.1 \%$; for empty containers and transshipment containers, it is $0.5 \%$.

(4) For ease of calculation, vessels on the three routes are all assumed to be coming to Taiwan from the same port. The fixed costs for each terminal operator and other transaction costs are given in Table 2 .

(5) Damage rates, cost of land haulage and average costs 
Table 3. Other costs per container.

\begin{tabular}{|c|c|c|c|c|c|c|c|c|c|}
\hline \multirow{2}{*}{$\begin{array}{c}\text { Operator } \\
\left(y_{j}\right)\end{array}$} & \multicolumn{3}{|c|}{ Damage rate $\left(q_{i j}\right)$} & \multicolumn{3}{c|}{ Costs external to the port $\left(d_{i j}\right)$} & \multicolumn{3}{c|}{ Costs associated with damages $\left(a_{i j}\right)$} \\
\cline { 2 - 10 } & Full & Empty & Transshipment & Full & Empty & Transshipment & Full & Empty & Transshipment \\
\hline$y_{1}$ & $4.80 \%$ & $2.40 \%$ & $0.80 \%$ & 2,000 & 1,000 & 0 & 50,000 & 20,000 & 55,000 \\
\hline$y_{2}$ & $5.40 \%$ & $3.15 \%$ & $0.45 \%$ & 1,400 & 800 & 0 & 65,000 & 15,000 & 60,000 \\
\hline$y_{3}$ & $4.40 \%$ & $2.20 \%$ & $4.40 \%$ & 1,000 & 600 & 0 & 45,000 & 10,000 & 70,000 \\
\hline$y_{4}$ & $4.20 \%$ & $2.10 \%$ & $0.70 \%$ & 2,000 & 1,000 & 0 & 30,000 & 8,000 & 65,000 \\
\hline$y_{5}$ & $5.40 \%$ & $3.15 \%$ & $0.45 \%$ & 1,400 & 800 & 0 & 40,000 & 17,000 & 55,000 \\
\hline$y_{6}$ & $4.00 \%$ & $2.00 \%$ & $4.00 \%$ & 1,000 & 600 & 0 & 55,000 & 14,000 & 50,000 \\
\hline
\end{tabular}

Table 4. Discounts and capacities for terminal operators.

\begin{tabular}{|c|c|c|c|c|c|}
\hline \multirow{2}{*}{ Operator $\left(y_{j}\right)$} & \multicolumn{2}{|c|}{ Volume discounts } & \multirow{2}{*}{$\begin{array}{l}\text { Dwelling time } \\
\text { (hours) }\left(l_{i j}\right)\end{array}$} & \multirow{2}{*}{$\begin{array}{c}\text { Annual capacity } \\
\text { (TEUs) }\left(V_{i j}\right)\end{array}$} & \multirow{2}{*}{$\begin{array}{l}\text { Hourly capacity } \\
\text { (move/hour) }\end{array}$} \\
\hline & Volume $(1,000$ TEUs $)\left(H_{i j}{ }^{k}\right)$ & Discount $\left(c_{i j}{ }^{k}\right)$ & & & \\
\hline \multirow{3}{*}{$y_{1}$} & $<20$ & 0.90 & \multirow{3}{*}{12} & \multirow{3}{*}{70,000} & \multirow{3}{*}{50} \\
\hline & $20-50$ & 0.80 & & & \\
\hline & $>50$ & 0.75 & & & \\
\hline \multirow{3}{*}{$y_{2}$} & $<10$ & 0.95 & \multirow{3}{*}{15} & \multirow{3}{*}{50,000} & \multirow{3}{*}{60} \\
\hline & $10-30$ & 0.90 & & & \\
\hline & $>30$ & 0.80 & & & \\
\hline \multirow{3}{*}{$y_{3}$} & $<30$ & 0.90 & \multirow{3}{*}{12} & \multirow{3}{*}{100,000} & \multirow{3}{*}{55} \\
\hline & $30-60$ & 0.80 & & & \\
\hline & $>60$ & 0.70 & & & \\
\hline \multirow{3}{*}{$y_{4}$} & $<20$ & 0.95 & \multirow{3}{*}{13} & \multirow{3}{*}{80,000} & \multirow{3}{*}{45} \\
\hline & $20-40$ & 0.85 & & & \\
\hline & $>40$ & 0.80 & & & \\
\hline \multirow{3}{*}{$y_{5}$} & $<10$ & 0.95 & \multirow{3}{*}{11} & \multirow{3}{*}{40,000} & \multirow{3}{*}{65} \\
\hline & $10-30$ & 0.90 & & & \\
\hline & $>30$ & 0.75 & & & \\
\hline \multirow{3}{*}{$y_{6}$} & $<50$ & 0.85 & \multirow{3}{*}{10} & \multirow{3}{*}{120,000} & \multirow{3}{*}{50} \\
\hline & $50-70$ & 0.80 & & & \\
\hline & $>70$ & 0.70 & & & \\
\hline
\end{tabular}

associated with damages are given in Table 3.

(6) Discounts and Handling charge are taken to be equal for all cargo types. Terminal operator capacities are totals for all three cargo types, as in Table 4. Published tariffs are given in Table 5.

\section{Parameters Setting}

This paper tests the parameters of PSO algorithm, mainly including termination condition, number of particle swarms, acceleration coefficients $\left(c_{1}, c_{2}\right)$ and inertia weight $w$. Moreover, the method to generate the initial solution will also be discussed accordingly. The termination condition is first analyzed.

\section{1) Number of Evaluations}

To suppose that the number of particle swarms is 10, learning factors $c_{1}=c_{2}=2$, and inertia weight $w=0.8$, by testing termination condition between 500 and 1,500 evaluations, the results of final objective value varied as Table 6 .

From Table 6 , it is found that the better results are produced at number of evaluations equal 600,900 , and 1,000 respectively. Usually the more computation time will gain better results. But it is not sustained in this case. The reason might be the less number of particle swarms to reduce the stability of solutions. In this paper the number of evaluations of PSO is chosen at 1,000 and the computing time of solution takes about 0.06 seconds with number of evaluations between 900 and 1,000 .

\section{2) Number of Particle Swarms}

From the analytical results on termination condition, the number of evaluations is chosen to be 1,000 . Supposing that the acceleration coefficients $c_{1}=c_{2}=2$, and inertia weight $w=$ 0.8 , by testing the number of particle swarms between 10 and 100 , the final objective value varied as Table 7. And the optimal number of particle swarms is 40 . 
Table 5. Published tariff.

\begin{tabular}{|c|c|c|c|}
\hline \multirow{2}{*}{ Operator $\left(y_{j}\right)$} & \multicolumn{3}{|c|}{ Tariff (NTD/TEU) } \\
\cline { 2 - 4 } & Full & Empty & Transshipment \\
\hline$y_{1}$ & 3,500 & 2,800 & 3,000 \\
\hline$y_{2}$ & 3,400 & 2,800 & 3,200 \\
\hline$y_{3}$ & 2,500 & 2,000 & 2,000 \\
\hline$y_{4}$ & 3,500 & 2,800 & 3,000 \\
\hline$y_{5}$ & 3,400 & 2,800 & 3,200 \\
\hline$y_{6}$ & 2,500 & 2,000 & 2,000 \\
\hline
\end{tabular}

Table 6. Test results on termination condition $(w=0.8$, $c_{1}=2$, and $c_{2}=2$ ).

\begin{tabular}{|c|c|c|c|}
\hline $\begin{array}{c}\text { Number of } \\
\text { particle swarm }\end{array}$ & $\begin{array}{c}\text { Number of } \\
\text { evaluations }\end{array}$ & $\begin{array}{c}\text { Final objective } \\
\text { value }\end{array}$ & $\begin{array}{c}\text { Running time } \\
\text { (Sec.) }\end{array}$ \\
\hline 10 & 500 & $931,050,000$ & 0.031 \\
\hline $\mathbf{1 0}$ & $\mathbf{6 0 0}$ & $\mathbf{9 2 9 , 2 7 5 , 0 0 0}$ & $\mathbf{0 . 0 4 7}$ \\
\hline 10 & 700 & $929,500,000$ & 0.031 \\
\hline 10 & 800 & $931,050,000$ & 0.078 \\
\hline $\mathbf{1 0}$ & $\mathbf{9 0 0}$ & $\mathbf{9 2 9 , 2 7 5 , 0 0 0}$ & $\mathbf{0 . 0 6 2}$ \\
\hline $\mathbf{1 0}$ & $\mathbf{1 , 0 0 0}$ & $\mathbf{9 2 9 , 2 7 5 , 0 0 0}$ & $\mathbf{0 . 0 6 3}$ \\
\hline 10 & 1,100 & $931,050,000$ & 0.062 \\
\hline 10 & 1,200 & $929,500,000$ & 0.062 \\
\hline 10 & 1,300 & $931,050,000$ & 0.094 \\
\hline 10 & 1,400 & $929,819,640$ & 0.094 \\
\hline
\end{tabular}

Table 7. Test results on number of particle swarms $(w=$ $0.8, c_{1}=2$, and $c_{2}=2$ ).

\begin{tabular}{|c|c|c|c|}
\hline $\begin{array}{c}\text { Number of } \\
\text { particle swarm }\end{array}$ & $\begin{array}{c}\text { Number of } \\
\text { evaluations }\end{array}$ & $\begin{array}{c}\text { Final objective } \\
\text { value }\end{array}$ & $\begin{array}{c}\text { Running time } \\
\text { (Sec.) }\end{array}$ \\
\hline 10 & 1,000 & $929,275,000$ & 0.063 \\
\hline 20 & 1,000 & $929,275,000$ & 0.109 \\
\hline 30 & 1,000 & $929,400,000$ & 0.172 \\
\hline 40 & 1,000 & $\mathbf{8 7 9 , 4 0 0 , 0 0 0}$ & 0.219 \\
\hline 50 & 1,000 & $931,050,590$ & 0.312 \\
\hline 60 & 1,000 & $929,500,000$ & 0.329 \\
\hline 70 & 1,000 & $897,900,000$ & 0.390 \\
\hline 80 & 1,000 & $907,200,000$ & 0.438 \\
\hline 90 & 1,000 & $929,275,000$ & 0.500 \\
\hline 100 & 1,000 & $919,500,000$ & 0.656 \\
\hline
\end{tabular}

\section{3) Acceleration Coefficients $c_{1}$ and $c_{2}$}

According to the above analysis on number of particle swarms and termination condition, with settings of the number of particle swarms being 10, acceleration coefficients $c_{1}=c_{2}=$ 2 , and inertia weight $w=0.8$, we compare the results by different combinations of $c_{1}$ and $c_{2}$ ranging from 2 to 5 . From the results shown in Table 8 , it is found that $c_{1}$ and $c_{2}$ have tiny impacts on the results under the setting conditions. Therefore, the parameters $c_{1}=c_{2}=2$ are accepted in this paper.

\section{4) Inertia Weight (w)}

Inertia Weight $(w)$ was not taken into consideration when
Table 8. Test results of $c_{1}$ and $c_{2}$ (number of particle swarm $=$ 40; number of evaluations $=1,000)$.

\begin{tabular}{|c|c|c|c|c|}
\hline$w$ & $c_{1}$ & $c_{2}$ & The final objective value & Running time (Sec.) \\
\hline 0.8 & 2 & 2 & $\mathbf{8 7 9 , 4 0 0 , 0 0 0}$ & 0.406 \\
\hline 0.8 & 2 & 3 & $\mathbf{8 7 9 , 4 0 0 , 0 0 0}$ & 0.438 \\
\hline 0.8 & 2 & 4 & $931,050,000$ & 0.594 \\
\hline 0.8 & 2 & 5 & $\mathbf{8 7 9 , 4 0 0 , 0 0 0}$ & 0.437 \\
\hline 0.8 & 3 & 2 & $\mathbf{8 7 9 , 4 0 0 , 0 0 0}$ & 0.438 \\
\hline 0.8 & 3 & 3 & $\mathbf{8 7 9 , 4 0 0 , 0 0 0}$ & 0.687 \\
\hline 0.8 & 3 & 4 & $\mathbf{8 7 9 , 4 0 0 , 0 0 0}$ & 0.609 \\
\hline 0.8 & 3 & 5 & $\mathbf{8 7 9 , 4 0 0 , 0 0 0}$ & 0.500 \\
\hline 0.8 & 4 & 2 & $\mathbf{8 7 9 , 4 0 0 , 0 0 0}$ & 0.484 \\
\hline 0.8 & 4 & 3 & $\mathbf{8 7 9 , 4 0 0 , 0 0 0}$ & 0.563 \\
\hline 0.8 & 4 & 4 & $\mathbf{8 7 9 , 4 0 0 , 0 0 0}$ & 0.500 \\
\hline 0.8 & 4 & 5 & $\mathbf{8 7 9 , 4 0 0 , 0 0 0}$ & 0.546 \\
\hline 0.8 & 5 & 2 & $\mathbf{8 7 9 , 4 0 0 , 0 0 0}$ & 0.547 \\
\hline 0.8 & 5 & 3 & $\mathbf{8 7 9 , 4 0 0 , 0 0 0}$ & 0.532 \\
\hline 0.8 & 5 & 4 & $\mathbf{8 7 9 , 4 0 0 , 0 0 0}$ & 0.687 \\
\hline 0.8 & 5 & 5 & $\mathbf{8 7 9 , 4 0 0 , 0 0 0}$ & 0.563 \\
\hline
\end{tabular}

Table 9. Test results of parameter $w$ (number of particle swarms $=40$; number of evaluations $=1,000$ ).

\begin{tabular}{|c|c|c|c|c|}
\hline$w$ & $c_{1}$ & $c_{2}$ & The final objective value & Running time (Sec.) \\
\hline 0.5 & 2 & 2 & $\mathbf{8 7 9 , 4 0 0 , 0 0 0}$ & 0.718 \\
\hline 0.6 & 2 & 2 & $\mathbf{8 7 9 , 4 0 0 , 0 0 0}$ & 0.766 \\
\hline 0.7 & 2 & 2 & $\mathbf{8 7 9 , 4 0 0 , 0 0 0}$ & 0.828 \\
\hline 0.8 & 2 & 2 & $\mathbf{8 7 9 , 4 0 0 , 0 0 0}$ & 0.719 \\
\hline 0.9 & 2 & 2 & $\mathbf{8 7 9 , 4 0 0 , 0 0 0}$ & 0.609 \\
\hline 1.0 & 2 & 2 & $\mathbf{8 7 9 , 4 0 0 , 0 0 0}$ & 0.657 \\
\hline 1.1 & 2 & 2 & $\mathbf{8 7 9 , 4 0 0 , 0 0 0}$ & 0.640 \\
\hline 1.2 & 2 & 2 & $\mathbf{8 7 9 , 4 0 0 , 0 0 0}$ & 0.594 \\
\hline 1.3 & 2 & 2 & $\mathbf{8 7 9 , 4 0 0 , 0 0 0}$ & 0.687 \\
\hline 1.4 & 2 & 2 & $\mathbf{8 7 9 , 4 0 0 , 0 0 0}$ & 0.625 \\
\hline
\end{tabular}

PSO was proposed by Eberhart and Kennedy [4]. It was proposed by Shi and Eberhart [11], they demonstrated that the Inertia Weight $(w)$ accelerates the process approaching to the global optimum in short way. And the attribute of $w$ is similar to the temperature value in Simulated Annealing approach; the global optimum could be found more probably while $w$ value ranges from 0.8 to 1.2 .

With conditions of the number of particle swarms being 40 , number of evaluations being 1,000 and acceleration coefficients $c_{1}=c_{2}=2$, testing the inertia weight $w$ between 0.5 and 1.4 , the final objective value receives no influence by $w$ as shown in Table 9. So it is set $w=0.8$ in this case study.

\section{5) Comparison on Methods for Generating the Initial Solution}

In Section 3 there are two methods designed for approaching to the initial solution: the first method a) is completely random to approach to the initial solution and the second method b) is the way to extreme the initial solution which means all container volume is supposed to allocate to the specific terminal operator. In Table 10, the difference is 
Table 10. Comparison on the impacts by different methods for generating the initial solution.

\begin{tabular}{|c|c|c|}
\hline Methods & a) & a) + b) \\
\hline $\begin{array}{c}\text { Final solution/average } \\
\text { (100 times) }\end{array}$ & $1.4203 \times 10^{11}$ & $\mathbf{9 0 9 , 5 6 1 , 1 6 2}$ \\
\hline $\begin{array}{c}\text { Optimum solution/times } \\
\text { (final solution) }\end{array}$ & $9 / 100$ & $\mathbf{1 4 / 1 0 0}$ \\
\hline $\begin{array}{c}\text { Feasible solution/times } \\
\text { (final solution) }\end{array}$ & $16 / 100$ & $\mathbf{1 0 0 / 1 0 0}$ \\
\hline
\end{tabular}

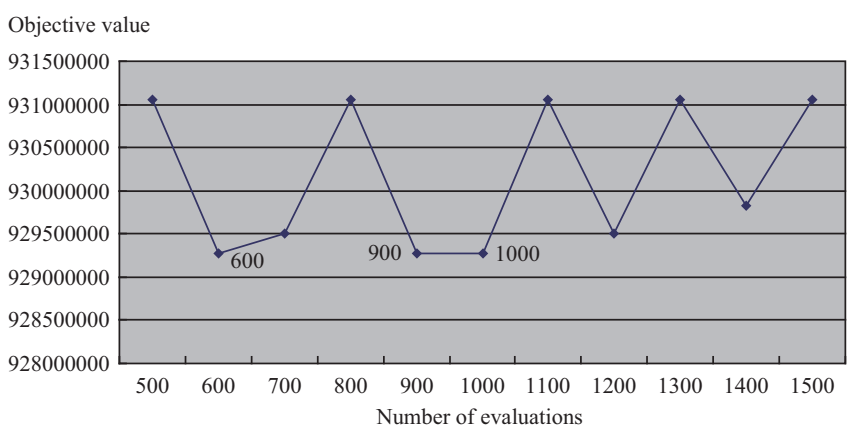

Fig. 3. Relationship between number of evaluations and final objective value, in case of number of particle swarms $=10$.

compared between the method a) and the method integrating a) and b), resulting by 100 times of computation respectively. From the same table, it is shown that simply taking the method a) is not well fitted to the feasible solution and consequently it locates the optimal solution with less times. On the opposite, the method integrating a) and b) may find the feasible solution every time and then the quality of solution is assured.

According to the testing results on parameters of termination condition, particle swarms, acceleration coefficients $\left(c_{1}\right.$, $c_{2}$ ), and inertia weight $(w)$, this paper finds that the designed PSO is less sensitive to parameters of acceleration coefficients $\left(c_{1}, c_{2}\right)$ and inertia weight $(w)$ which bring evident impacts on the solutions in the setting criteria.

On the other hand, parameters of termination condition and particle swarms, as well as the methods for generating the initial solution have more impacts on the solutions. The testing results on termination condition with number of particle swarms being 10 (Fig. 3) shows that the increased number of evaluations do not result in better solutions. While the number of particle swarms is increased to 40, as shown in Fig. 4, the solution eventually approaches to stable convergence. Consequently, it is known that the number of particle swarms could contribute to approaching stably to solution in certain levels.

However, the increased number of particle swarms does not bring better solutions. The reason might be that in the methods for generating the initial solution (see Sec. 3), the method b) only produces $\mathrm{m}$ groups of solutions in the way of however the number of particle swarms is increased even the method b) has great influence on the solution. Consequently, in case the initial solution from method a) is increased, it would not

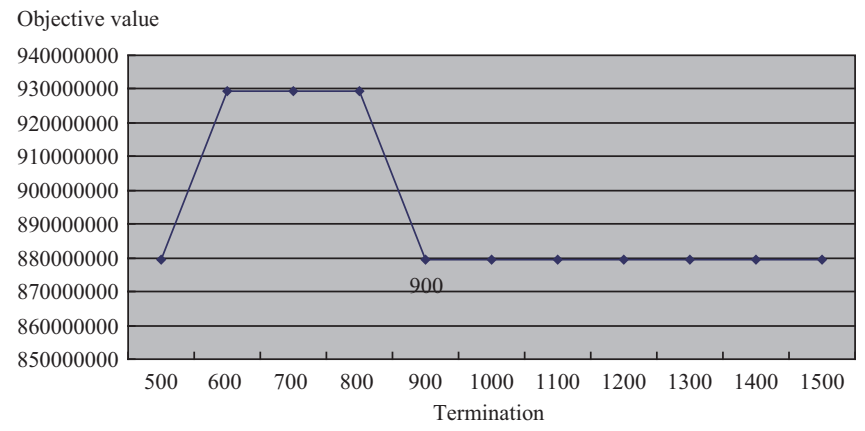

Fig. 4. Relationship between termination times and final objective value, in case of number of particle swarms $=40$.

guarantee to gain better solution. Through the experiment and analysis of parameters, this paper proposes the best set of parameters to be, number of particle swarms $=40$, number of evaluations $=1,000$, acceleration coefficients $c_{1}=c_{2}=2$ and inertia weight $w=0.8$.

Based on the parameters setting concluded above, the optimal solution can be solved and listed in Table 11. The decision variables $x_{j}$ and $y_{j}$ show that only two terminal operators are chosen, the full (120,000 TEUs) and empty (50,000 TEUs) containers are allocated to terminal operator $y_{6}$ while the transshipment containers $(60,000$ TEUs) are allocated to terminal operator $y_{1}$. The objective value is $879,400,000$ NTD.

\section{CONCLUSION}

This paper formulates the terminal operator selection problem using the MIP model and applies the PSO algorithm to solve the optimal solution. The mathematical model incorporates inland shipping costs and cargo losses into total costs in the objective function. Loading/unloading efficiency and pre-entry waiting time are included in the constraints to determine whether the operator meets the threshold minimum standards. In order to reduce the complexity of the model, all terminal operators are assumed to meet carriers' minimum standards in the other attributes. The total cost function of using a port is formulated as follows: fixed costs associated with using the terminal (including the costs of travel from the previous port to the current port, as well as port costs); transaction costs; fixed costs from loading damages; costs associated with different types and quantities of cargo; variable costs that are incurred outside the port (freight haulage and distribution center costs); variable costs associated with damage to cargo from loading damages. This paper demonstrates the analytical process of the terminal operator selection model by a worked example.

The parameters setting for PSO algorithm reveals that, with conditions of the seed of random number being 100, number of particle swarms being 10, acceleration coefficients $c_{1}=c_{2}=$ 2 and inertia weight $w=0.8$, by testing the number of evaluations between 500 and 1,500, it gains better results of final 
Table 11. The optimal solution.

\begin{tabular}{|c|c|c|c|c|c|c|c|}
\hline \multicolumn{8}{|c|}{ Optimal objective value: $879,400,000$} \\
\hline \multicolumn{8}{|c|}{$x_{j}$} \\
\hline$M=6, n=3$ & $y_{1}$ & $y_{2}$ & $y_{3}$ & $y_{4}$ & $y_{5}$ & $y_{6}$ & Demand \\
\hline Loaded container & 0 & 0 & 0 & 0 & 0 & 120,000 & 120,000 \\
\hline Empty container & 0 & 0 & 0 & 0 & 0 & 50,000 & 50,000 \\
\hline Transshipment container & 60,000 & 0 & 0 & 0 & 0 & 0 & 60,000 \\
\hline \multicolumn{8}{|c|}{$y_{j}$} \\
\hline Valuable $y_{j}$ & 1 & 0 & 0 & 0 & 0 & 1 & \\
\hline
\end{tabular}

objective value while number of evaluations at 600,900 and 1,000 . Increasing the number of evaluations usually brings better stability of solutions, this paper chooses the termination condition at 1,000 evaluations. Based on given termination condition, the settings of acceleration coefficients $c_{1}=c_{2}=2$ and inertia weight $w=0.8$, the optimal solution for particle swarms is at 40 by testing the variation of final objective value while particle swarms varies from 10 to 100 . As to acceleration coefficients $c_{1}$ and $c_{2}$, based on the parameters setting: number of particle swarms being 40 , number of evaluations being 1,000 and inertia weight $w=0.8$, it is found that $c_{1}$ and $c_{2}$ have tiny impacts on the results by comparing the combination of $c_{1}$ and $c_{2}$ ranging from 2 to 5 . Thus, this paper accepts acceleration coefficients $c_{1}=c_{2}=2$ as parameters setting. For inertia weight $w$, setting number of particle swarms to 40 , number of evaluations to 1,000 and $c_{1}=c_{2}=2$, the final objective value results in the same by varies inertia weight $w$ between 0.5 and 1.4. In consequence, we set the parameter $w=0.8$. Evaluating the methods for generating the initial solution, this paper finds that the feasible solution could be reached every time through the combination of two methods. The quality of solution could be secured by that.

By analyzing the parameters of termination condition, particle swarms, acceleration coefficients $\left(c_{1}, c_{2}\right)$, and inertia weight $w$, the designed PSO is less sensitive to acceleration coefficients and inertia weight, which have no significant impacts on the solution. While the parameters of termination condition and particle swarms, as well as methods for generating the initial solution have more significant impacts on the solution. Based on the parameters setting, the optimal solution solved reveals that the full (120,000 TEUs) and empty containers $(50,000 \mathrm{TEUs})$ are allocated to terminal operator $y_{6}$ while the transshipment containers $(60,000 \mathrm{TEUs})$ to $y_{1}$. This selection can minimize the total cost of $879,400,000$ NTD.

The analytical results of the worked example show that the best partnership for container carriers could be identified in the allocation of full, empty and transshipment containers in terminal operations. It also reveals that the terminal operator selection problem formulated as a MIP model using the revised PSO technique to solve the optimal solution is workable. Besides, the assumptions of the MIP model proposed in this paper may not conform to the real situation of the terminal operator selection problem, we suggest some relaxation of the assumptions can be considered as a future research topic.

\section{REFERENCE}

1. Benton, W. C., "Quantity discount decisions under conditions of multiple items, multiple suppliers and resource limitations," International Journal of Production Research, Vol. 29, pp. 1953-1961 (1991).

2. D'Este, G. M. and Meyrick, S., "Carrier selection in a RO/RO ferry trade: Part 1. Decision factors and attitudes," Maritime Policy \& Management, Vol. 19, pp. 115-126 (1992).

3. D'Este, G. M. and Meyrick, S., "Carrier selection in a RO/RO ferry trade: Part 2. Conceptual framework for the decision process," Maritime Policy \& Management, Vol. 19, pp. 127-138 (1992).

4. Eberhart, R. and Kennedy, J., "A new optimizer using particle swarm theory," Proceedings of the Sixth International Symposium on Micro Machine and Human Science, Nagoya, Japan, pp. 39-43 (1995).

5. $\mathrm{Hu}, \mathrm{X}$. and Eberhart, R., "Multiobjective optimization using dynamic neighborhood particle swarm optimization," Proceedings of the 2002 Congress on Evolutionary Computation, Honolulu, HI, pp. 1677-1681 (2002).

6. Jayaraman, V., Srivastava, R., and Benton, W. C., "Supplier selection and order quantity allocation: a comprehensisve model," Journal of Supply Chain Management, Vol. 35, pp. 50-58 (1999).

7. Kasilingam, R. G. and Lee, C. P., "Selection of vendors: a mixed-integer programming approach," Computers \& Industrial Engineering, Vol. 31, pp. 347-350 (1996).

8. Kennedy, J. and Eberhart, R. C., "Particle swarm optimization," Proceedings of the IEEE International Conference on Neural Networks, Perth, WA, Australia, pp. 1942-1948 (1995).

9. Lin, J. W., The Ship Operator's Behavior on Using Port Service, Master Thesis, Department of Shipping and Transportation Management, (1998).

10. Malchow, M. B., An Analysis of Port Selection, Ph.D. Dissertation, Institute of Transportation Studies, University of California, Berkeley, CA (2001).

11. Shi, Y. and Eberhart, R. C., "A modified particle swarm optimizer," Proceedings of the IEEE International Conference on Evolutionary Computation, Anchorage, AK, USA, pp. 69-73 (1998).

12. Shiau, F. J., Developing a Hierarchical Particle Swarm Based Fuzzy Decision Tree Algorithm, Master Thesis, Department of Industrial Engineering and Management, Yuan-Ze University, Taiwan (2005).

13. Slack, B., "Containerization, inter-port competition and port selection," Maritime Policy \& Management, Vol. 12, pp. 293-303 (1985).

14. Tongzon, J. L., "Port choice and freight forwarders," Transportation Research Part E, Vol. 45, pp. 186-195 (2009).

15. Yeh, L. W., Optimal Procurement Policies for Multi-Supplier with Capacity Constraint and Price Discount, Master Thesis, Yuan-Ze University (2002). 